\title{
Parametric Study on Phase Change Material Based Thermal Energy Storage System
}

\author{
Kondakkagari Dharma Reddy*, Pathi Venkataramaiah, Tupakula Reddy Lokesh \\ Department of Mechanical Engineering, S. V. University, Tirupati, India \\ Email: ${ }^{*}$ kdharmareddy@gmail.com
}

Received 18 October 2014; revised 10 November 2014; accepted 25 November 2014

Copyright $@ 2014$ by authors and Scientific Research Publishing Inc.

This work is licensed under the Creative Commons Attribution International License (CC BY). http://creativecommons.org/licenses/by/4.0/

(c) (i) 0 pen Access

\begin{abstract}
The usage of phase change materials (PCM) to store the heat in the form of latent heat is increased, because large quantity of thermal energy is stored in smaller volumes. In the present experimental investigation, sodium thiosulphate pentahydrate is employed as phase change material and it is stored in stainless steel capsules. These capsules are kept in fabricated tank and hot water is supplied into it. The experimental design is prepared by considering the parameters: flow rate, heat transfer fluid inlet temperature and PCM capsule shape. Experiments are conducted according to the experimental design and responses are recorded. The effect of selected parameters on TES using PCM is studied by analyzing experimental data. The experimental data are also analyzed using Fuzzy Logic to find the optimal values of flow rate, heat transfer fluid inlet temperature and PCM capsule shapes. The present work utilizes Fuzzy Logic to find the optimal parameters for designing the effective Thermal Energy Storage System (TES).
\end{abstract}

\section{Keywords}

Phase Change Material (PCM), Thermal Energy Storage System, Fuzzy Logic

\section{Introduction}

The continuous increase in the level of greenhouse emissions and the rise in fuel prices are the main driving forces behind efforts to more effective utilization of various sources of renewable energy. Energy storage units can be used to reduce energy consumption by using available waste heat or alternate energy sources.

This also leads to saving of primary fuels and makes the system more cost effective by reducing the wastage of energy. The energy storage can also even out the mismatch between energy supply and consumption and thereby helps in saving capital costs. Thermal energy storage (TES) is one of the key technologies for energy conservation and is used to assist in the effective utilization of thermal energy in a wide number of applications.

\footnotetext{
${ }^{*}$ Corresponding author.
}

How to cite this paper: Reddy, K.D., Venkataramaiah, P. and Lokesh, T.R. (2014) Parametric Study on Phase Change Material Based Thermal Energy Storage System. Energy and Power Engineering, 6, 537-549. 


\section{Literature Review and Objective}

The behavior of a packed bed latent heat thermal energy storage system is analyzed. The packed bed utilizes the spherical capsules filled with paraffin wax as phase change material (PCM) usable with solar water heating system. The equations are numerically solved, and the results obtained are used for the thermal performance analysis of both charging and discharging process. The effect of inlet heat transfer fluid temperature (Steffan number), mass flow rate and phase change temperature on the thermal performance of capsules of different radii have been investigated [1]. The application of Taguchi's robust design coupled with fuzzy based desirability function approach for optimizing multiple bead geometry parameters of submerged arc weldment and Fuzzy inference system has been adapted to avoid uncertainly, imprecision and vagueness in experimentation as well as in data analysis by traditional Taguchi based optimization approach [2].

The solar water heating system incorporating with phase change materials (PCMs) had been investigated [3]. An attempt was made to investigate and analyze the available thermal energy storage systems Incorporating PCMs for use in different applications. [4] investigated and analyzed the thermal energy storage extracted from solar heater and use for domestic purpose and Phase change materials as paraffin wax and sodium acetate try hydrate are used for storing thermal energy in two different insulation tanks [5]. A spherical container, filled with spheres containing either paraffin wax or stearic acid as Phase Change Materials (PCM) and water occupying the space left between the spheres had been studied and ANSYS is used for modeling the PCM inside the spheres with simple 2D. [6] studied the feasibility of storing solar energy using Phase Change Materials (PCMs) and utilizing this energy to heat water for domestic purposes during night time and this ensures that hot water is available throughout the day. The storage unit utilizes small cylinders, made of aluminium, filled with paraffin wax as the heat storage medium. [7] implemented and tested thermal energy storage (TES) system using different phase change materials (PCM) for solar cooling and refrigeration applications. A high temperature pilot plant is able to test different types of TES systems and uses synthetic thermal oil as heat transfer fluid (HTF). Two different PCM were selected after a deep study of the requirements of a real solar cooling plant and the available materials in the market, finally d-mannitol with phase change temperature of $167^{\circ} \mathrm{C}$ and hydroquinone which has a melting temperature of $172.2^{\circ} \mathrm{C}$ were used. [8] studied Fuzzy Logic integrated with the Taguchi method is used to optimize Wire Electro Discharge Machining (WEDM) process with multiple quality characteristics. The application of the Taguchi method with Fuzzy Logic was discussed to optimize the machining parameters for Wire electrical discharge machining of Inconel 825 with multiple characteristics. A multi-response performance index (MRPI) was used for optimization. The machining parameters viz., pulse on time, pulse off time, corner servo voltage, flushing pressure, wire feed, wire tensiospark gap voltage, servo feed were optimized with consideration of multiple performance characteristics. [9] combined Fuzzy Logic with the grey relational analysis, the designed algorithm is transformed into optimization of a single and simple grey-fuzzy reasoning grade rather than multiple performance characteristics. The Taguchi method is also adopted to search for an optimal combination of cutting parameters [10]. According to [11], solar water heater is getting popularity since they are relatively inexpensive and simple to fabricate and maintain. Studied building integrated solar energy collection system into the building shell and mechanical systems may reduce the cost of the solar energy systems and improve the efficiency of the collection. [12] developed a surface roughness prediction model using Fuzzy Logic for end milling of Al-SiCp metal matrix composite using carbide end mill cutter. The surface roughness is modeled as a function of spindle speed $(\mathrm{N})$, feed rate (f), depth of cut (d) and the SiCp percentage (S). The predicted values surface roughness is compared with experimental result. It is observed that surface roughness is most influenced by feed rate, spindle speed and SiC percentage. Depth of cut has least influence. [13] described the importance of Latent heat storage, according to his review Paraffin waxes are cheap and have moderate thermal energy storage density but low thermal conductivity and, hence, require a large surface area. Hydrated salts have a larger energy storage density and a higher thermal conductivity. [14] Described the basic requirements of phase change materials with respective to their most important properties like latent heat, density etc, advantages, and disadvantages. [15] studied three modes of thermal energy storage (TES), and these are sensible heat storage (SHS), latent heat storage (LHS), and bond energy storage (BES). The SHS refers to the energy systems that store thermal energy without phase change. Heating of a material that undergoes a phase change (usually melting) is called the LHS. In the LHS, the storage operates isothermally at the phase change of the material. Lastly, comparison of storage system types is also presented. [16] Optimized the drilling characteristics for Al/SiCp composites using Fuzzy Logic and genetic algorithms (GA) and thedrilling characteristics were drill wear, specific energy and surface roughness [17]. Deals with the melting phenomena of Phase Change 
Material (PCM) need to be understood for the design of thermal storage systems. The constrained and unconstrained melting of PCM inside a spherical capsule using paraffin wax (PW) is investigated. The experiments are carried out with different HTF temperatures of $62^{\circ} \mathrm{C}, 70^{\circ} \mathrm{C}, 75^{\circ} \mathrm{C}$ and $80^{\circ} \mathrm{C}$. [18] studied the feasibility of storing solar energy using phase change materials (PCMs) stored in small cylinders and utilizing this energy to heat water for domestic applications during night time. [19] discussed the physical reasons for phase changing property of a phase change material (PCMs) and some important applications of PCMs [20]. After a rigorous study of their properties like melting temperature, heat of fusion, thermal conductivity and density, a concluding list of nine promising phase changing materials appropriate for thermal energy storage is prepared [21].

The literature review reveals that no researcher was used the Fuzzy Logic technique for optimizing the thermal energy storage system parameters using different shapes of the capsules in which PCM is stored. In this research work, an attempt was made to determine the optimum levels of the parameters of thermal energy storage system using Fuzzy Logic.

\section{Experimental Setup}

A schematic diagram of the experimental set-up is shown in Figure 1. This consists of an insulated cylindrical TES tank, which contains PCM capsules (cylindrical, spherical, and square capsules), flow meter and water storage tank. The stainless steel TES tank has a capacity of 10 liters. The storage tank is insulated with glass wool of 50 mm thick. The PCM capsules of different shapes are uniformly packed in the storage tank. The $\mathrm{Na}_{2} \mathrm{~S}_{2} \mathrm{O}_{3} \cdot 5 \mathrm{H}_{2} \mathrm{O}$ is used as PCM that has a melting temperature of $48^{\circ} \mathrm{C}$ and latent heat of fusion of $210 \mathrm{~kJ} / \mathrm{kg}$. Water is used as both SHS material and HTF.

A flow meter with an accuracy of $\pm 2 \%$ is used to measure the flow rate of HTF and the flow rate is changed by different tap openings. The TES tank is incorporated with digital thermometers with an accuracy of $\pm 1^{\circ} \mathrm{C}$ is placed above the TES tank to measure the temperatures of HTF and PCM stored inside the capsules. An electric water heater is used to maintain the constant temperature in the water storage tank. The thermo-physical properties of PCM are given in Table 1.

1. Electric heater; 2. Constant temperature bath (water storage tank); 3 \& 8 Flow control valves; 4. Flow meter; 5. Distributer; 6. TES Tank; 7. PCM capsules; 9. Outlet tank; 10. Digital thermometer.

\subsection{Experimental Trail}

The experiments are carried out on the basis Taguchi design obtained from Minitab by considering the factors flow rate of HTF, HTF inlet temperature and PCM capsule shapes at different levels as shown in Table 2. And the measured responses i.e., charging time and discharging time is shown in Table 3.

Table 1. Thermo-physical properties of PCM.

\begin{tabular}{|c|c|c|c|c|c|c|}
\hline & \multirow{2}{*}{$\begin{array}{c}\text { Melting } \\
\text { temperature }\left({ }^{\circ} \mathrm{C}\right)\end{array}$} & \multirow{2}{*}{$\begin{array}{l}\text { Latent heat of } \\
\text { fusion }(\mathrm{kJ} / \mathrm{kg})\end{array}$} & \multicolumn{2}{|c|}{ Density $\left(\mathrm{kg} / \mathrm{m}^{3}\right)$} & \multicolumn{2}{|c|}{ Specific heat $\left(\mathrm{J} / \mathrm{kg} \cdot{ }^{\circ} \mathrm{C}\right)$} \\
\hline & & & Solid & Liquid & Solid & Liquid \\
\hline $\begin{array}{l}\text { Sodium thiosulfate pentahydrate } \\
\qquad\left(\mathrm{Na}_{2} \mathrm{~S}_{2} \mathrm{O}_{3} \cdot 5 \mathrm{H}_{2} \mathrm{O}\right)\end{array}$ & 48 & 210 & 1750 & 1670 & 2.38 & 1.46 \\
\hline
\end{tabular}

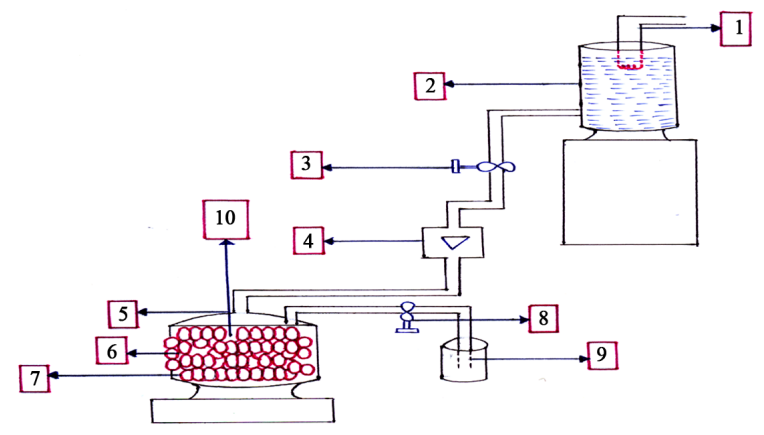

Figure 1. Schematic diagram of experimental setup. 
Table 2. Factors and their levels.

\begin{tabular}{ccccc}
\hline \multirow{2}{*}{ Sl. No } & & \multicolumn{3}{c}{ Factors } \\
\cline { 2 - 5 } & Levels & Flow rate (lit/min) & HTF inlet temperature $\left({ }^{\circ} \mathrm{C}\right)$ & PCM capsule shape \\
\hline $\mathbf{1}$ & $\mathbf{1}$ & 2 & 56 & Cylindrical \\
3 & 2 & 4 & 58 & Square \\
\end{tabular}

Table 3. Experimental layouts and measured response values.

\begin{tabular}{|c|c|c|c|c|c|}
\hline \multirow[b]{2}{*}{ Experimental run } & \multicolumn{3}{|c|}{ Inputs } & \multicolumn{2}{|c|}{ Responses } \\
\hline & Flow rate (lit/min) & HTF inlet temp $\left(\mathrm{T}_{\mathrm{HTF}}\right)\left({ }^{\circ} \mathrm{C}\right)$ & $\begin{array}{l}\text { PCM capsule } \\
\text { shape }\end{array}$ & $\begin{array}{l}\text { Charging time } \\
\text { (min) }\end{array}$ & $\begin{array}{l}\text { Discharging time } \\
\text { (min) }\end{array}$ \\
\hline 1 & 2 & 60 & 1 & 10 & 140 \\
\hline 2 & 2 & 60 & 2 & 32 & 140 \\
\hline 3 & 2 & 60 & 3 & 18 & 100 \\
\hline 4 & 2 & 58 & 1 & 14 & 100 \\
\hline 5 & 2 & 58 & 2 & 34 & 120 \\
\hline 6 & 2 & 58 & 3 & 18 & 80 \\
\hline 7 & 2 & 56 & 1 & 16 & 100 \\
\hline 8 & 2 & 56 & 2 & 36 & 100 \\
\hline 9 & 2 & 56 & 3 & 18 & 80 \\
\hline 10 & 4 & 60 & 1 & 08 & 140 \\
\hline 11 & 4 & 60 & 2 & 28 & 140 \\
\hline 12 & 4 & 60 & 3 & 12 & 100 \\
\hline 13 & 4 & 58 & 1 & 11 & 100 \\
\hline 14 & 4 & 58 & 2 & 32 & 120 \\
\hline 15 & 4 & 58 & 3 & 18 & 80 \\
\hline 16 & 4 & 56 & 1 & 16 & 100 \\
\hline 17 & 4 & 56 & 2 & 32 & 100 \\
\hline 18 & 4 & 56 & 3 & 18 & 80 \\
\hline
\end{tabular}

\subsection{Charging Process}

During the charging process (storing of heat energy), the HTF is circulated through the TES tank continuously. The HTF exchanges its energy to PCM capsules and at the beginning of the charging process, the temperature of the PCM $\left(\mathrm{T}_{\mathrm{PCM}}\right)$ inside the packed bed capsules is $32^{\circ} \mathrm{C}$, which is lower than the melting temperature. Initially the energy is stored inside the capsules as sensible heat until the PCM reaches its melting temperature. As the charging process proceeds, energy storage is achieved by melting the PCM at a constant temperature. Finally, the PCM becomes superheated. The energy is then stored as sensible heat in liquid PCM. Temperatures of the PCM and HTF are recorded at an interval of 2 minutes. The charging process is continued until the PCM temperature comes in equilibrium with the temperature of HTF in the TES tank. The key experimental parameters HTF inlet temperature, flow rate of HTF and PCM capsule shapes are studied by considering the charging time.

\subsection{Discharge Process}

The discharging process started after the completion of charging process. Batch wise discharging experiments are carried out. In this method, 2 liters of hot water is discharged from the thermal energy storage tank and the 
same quantity of cold water at $32^{\circ} \mathrm{C}$ is fed into TES tank in each batch. The average temperature of the collected discharge water in the bucket is measured using a digital thermometer. The time difference between the consequent discharges is $20 \mathrm{~min}$. The batch wise withdrawing of hot water is continued till the temperature of the outlet water reaches $32^{\circ} \mathrm{C}$. A comparative study is also made between the conventional SHS system and combined storage system (SHS + LHS).

\section{Results and Discussions}

\subsection{Charging Process}

\subsubsection{Effect of Flow Rate on Different PCM Capsules}

Figures 2-4 illustrate the effect of varying the mass flow rate of HTF (2 and 4 lit/min) during the charging of the storage tank. Increase in mass flow rate has a large influence on the phase transition process of PCM. As the flow rate increases, the time required to complete charging becomes smaller.

When the flow rate increases from two lit/min to four lit/min the charging time is reduced by $20 \%, 12.5 \%$ and $25 \%$ for cylindrical, spherical and square PCM capsules respectively. Hence, mass flow rate has a significant effect on the charging process of thermal energy storage tank.

\subsubsection{Effect of HTF Inlet Temperature on Different PCM Capsules}

Figures 5-7 indicate the effects of HTF inlet temperature on different capsule shapes when the HTF inlet

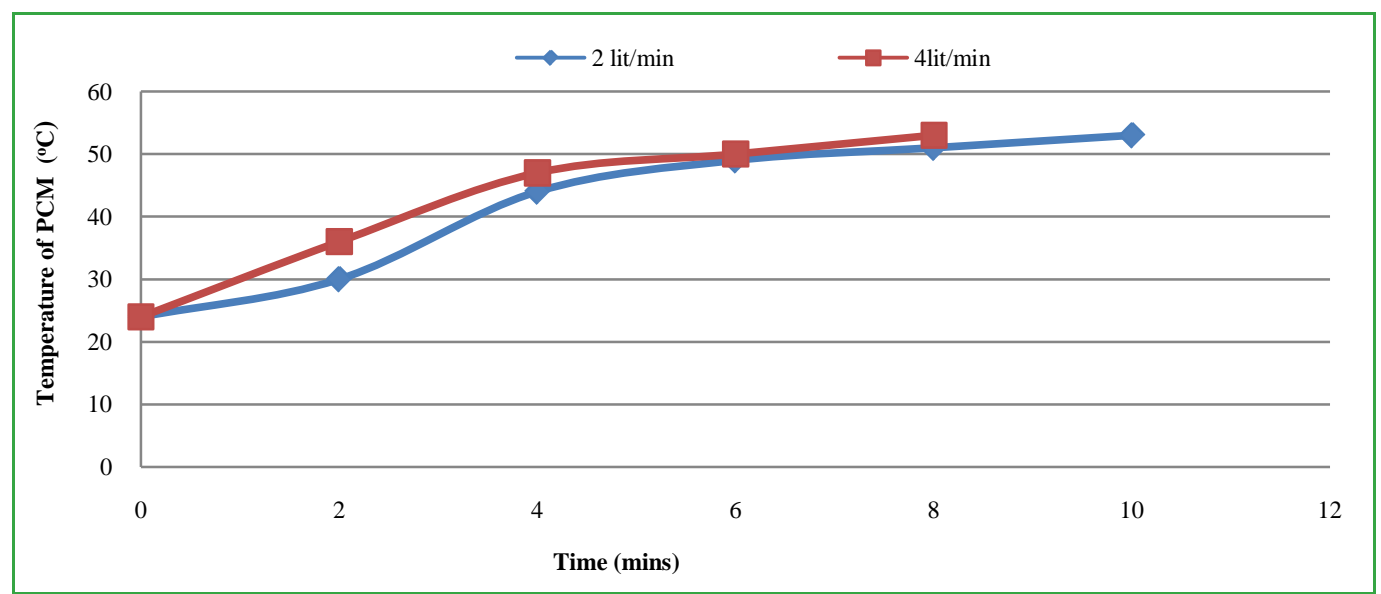

Figure 2. Effect of flow rates on cylindrical PCM capsules.

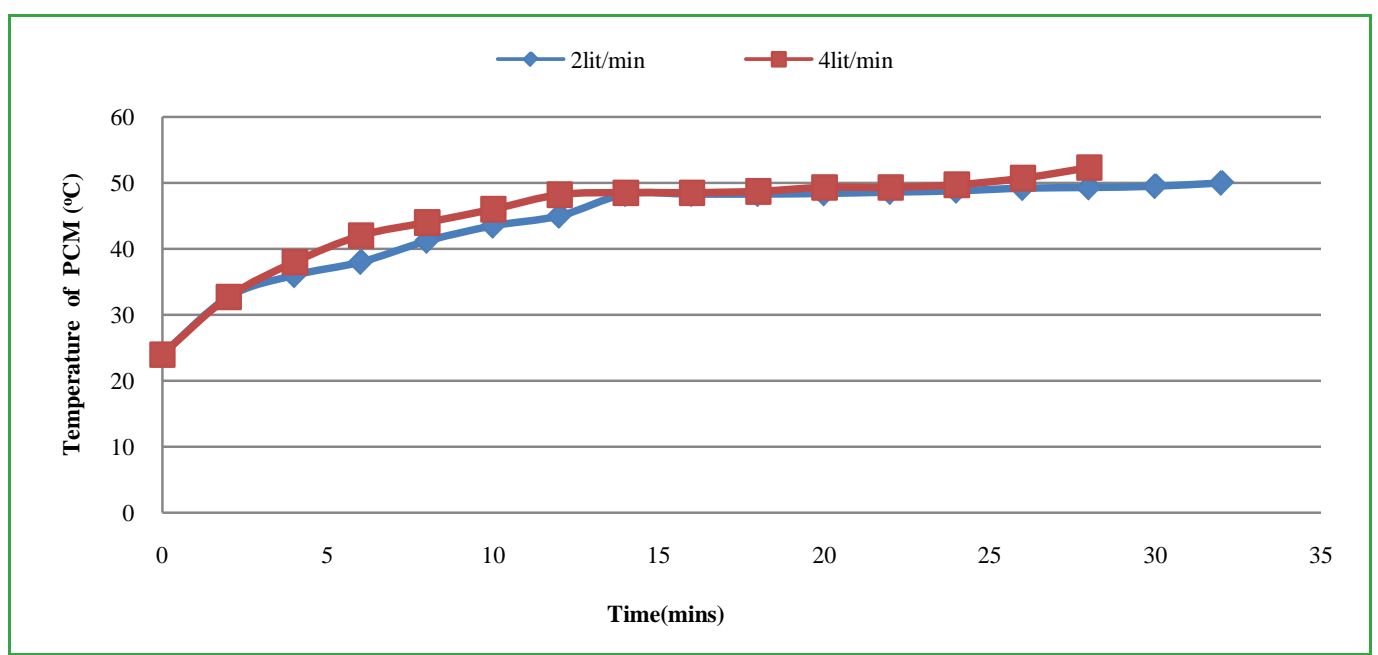

Figure 3. Effect of flow rates on spherical PCM capsules. 


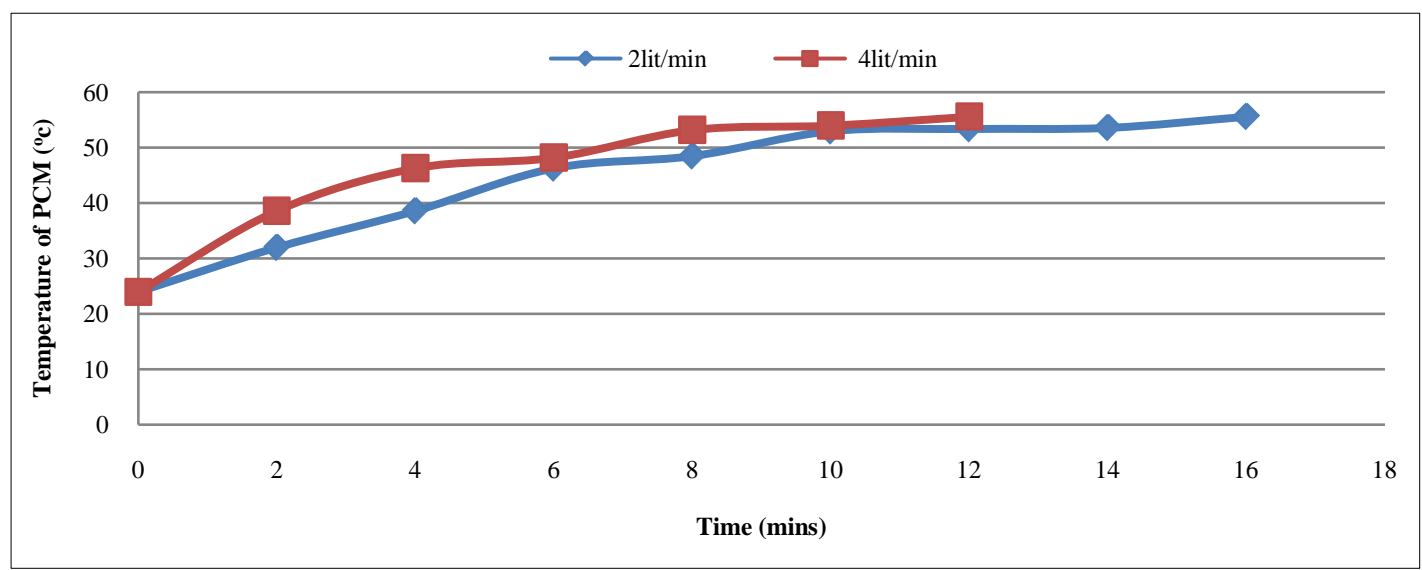

Figure 4. Effect of flow rates on square PCM capsules.

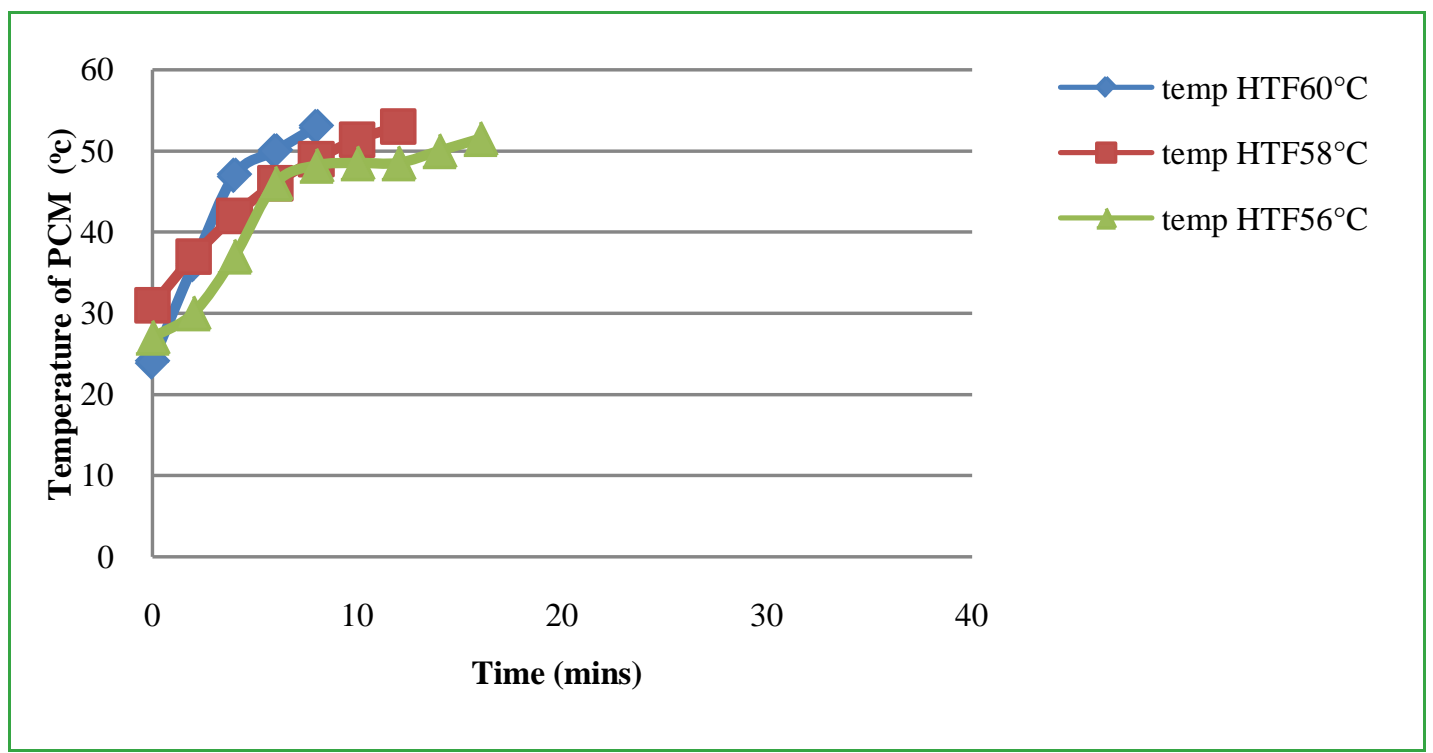

Figure 5. Effect of HTF inlet temperatures for cylindrical capsules.

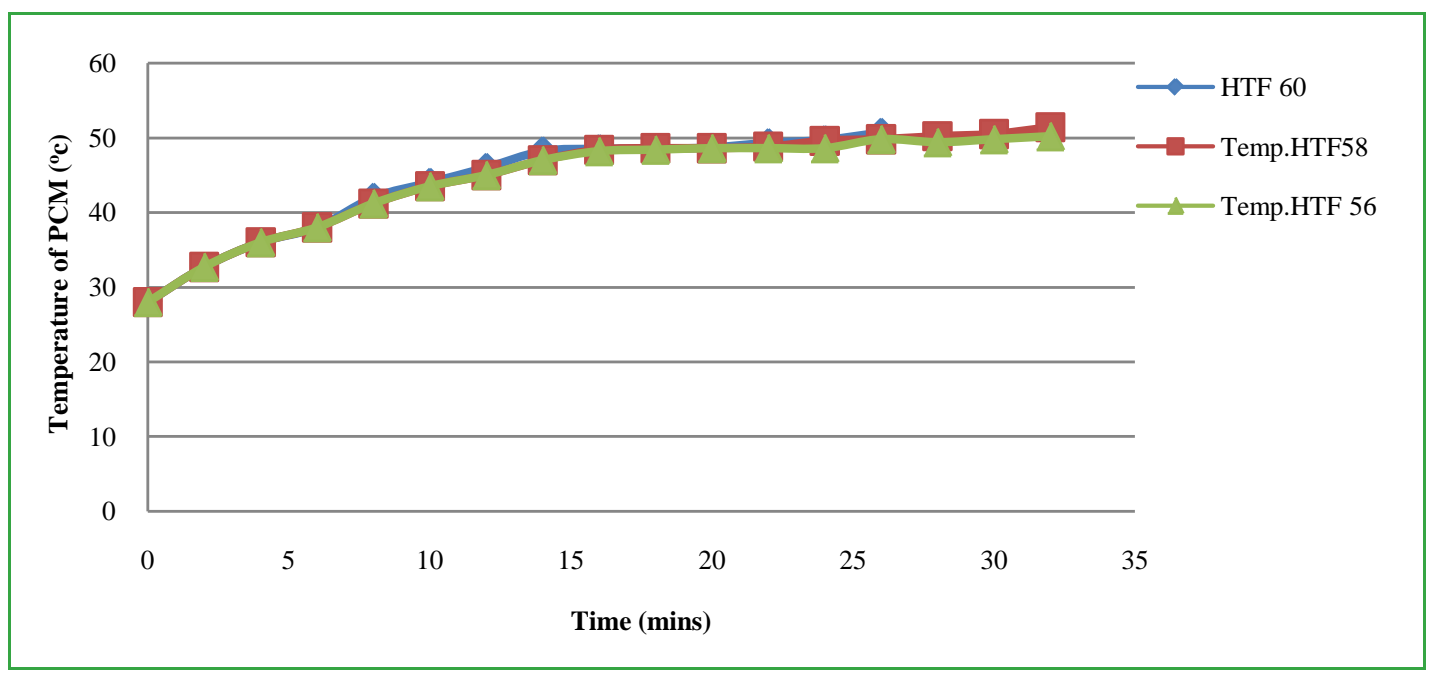

Figure 6. Effect of HTF inlet temperature for spherical capsules. 


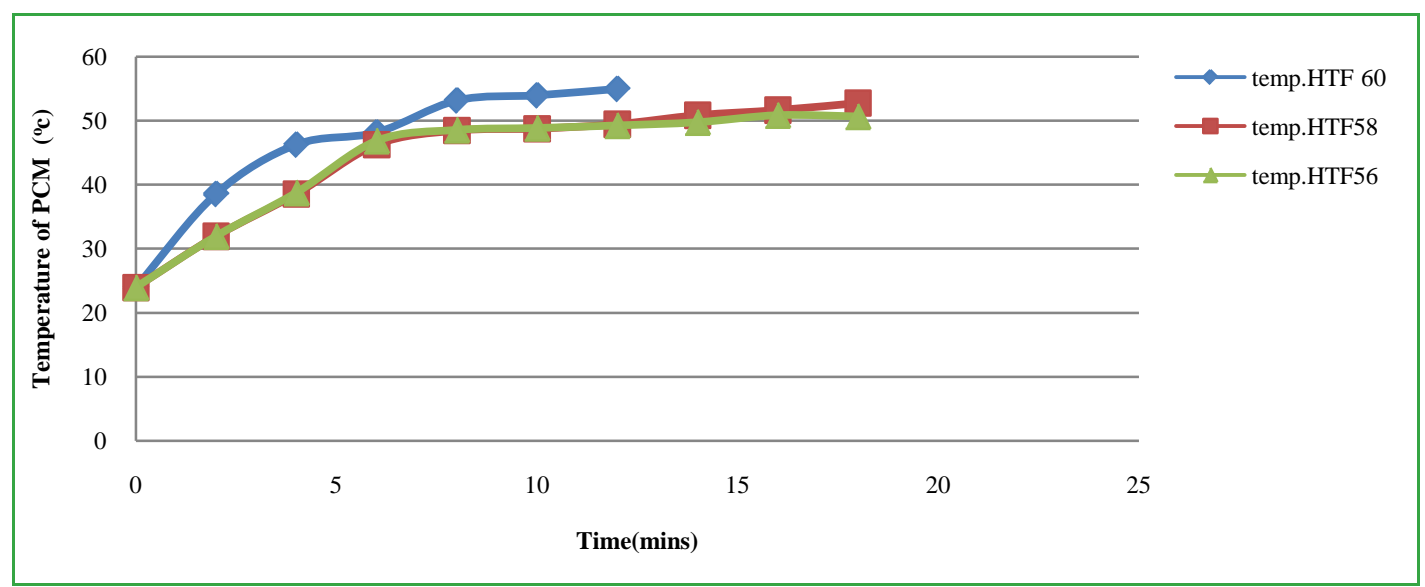

Figure 7. Effect of HTF inlet temperatures for square capsules.

temperature increases from $56^{\circ} \mathrm{C}$ to $60^{\circ} \mathrm{C}$. The charging process is reduced by $50 \%, 12.5 \%$ and $33.33 \%$ when cylindrical capsules, spherical capsules and square capsules are employed. These shows the charging time is strongly affected by the inlet temperature of heat transfer fluid. It is concluded that higher the inlet heat transfer fluid temperature, the shorter the time interval to complete charging process.

\subsubsection{Effect of Capsule Shape}

The effect of capsule shape is studied by considering the best flow rate and best heat transfer fluid inlet temperatures. The graphs shown below are drawn by considering $\mathrm{HTF}$ inlet temperature at $60^{\circ} \mathrm{C}$ and mass flow rate of HTF at 4 lit/min.

From Figure 8, it is observed that, the cylindrical capsules reduces the charging time by $71.43 \%, 33.33 \%$ when compared to spherical and square capsules respectively. And also surface area to volume ratio for cylindrical capsule (25 mm dia) is $180 \mathrm{~m}^{-1}$ and for spherical capsule (50 mm dia) is $120 \mathrm{~m}^{-1}$. And for square capsule is $33.33 \mathrm{~m}^{-1}$. Hence, it is concluded that capsule having high surface area to volume ratio absorbs more thermal energy in a given time one leading to lesser charging time, as it presents more surface area for a given volume. Hence cylindrical capsule is selected as the best capsule shape in which PCM is to be stored.

\subsubsection{Discharging Process}

In this process, a certain amount of hot water (say 2 lit) is withdrawn from the TES tank and same amount of water is fed into the TES tank and the temperature of withdrawn water is noted. The water is withdrawn from the TES tank for every 20 minutes. This entire process is called batch process. The same procedure is repeated for different capsule shapes. The discharging process is continued until the temperature of withdrawn water ( $\mathrm{T}_{\mathrm{W}}$ ) reached to $32^{\circ} \mathrm{C}$.

From Figure 9, it is observed that the energy retrieval time or discharging time is more for cylindrical capsules and spherical capsules when compared to square capsules and also same for cylindrical and spherical capsules. But cylindrical capsules require less charging time and have high surface area to volume ratio. Hence cylindrical capsule (25 mm dia.) is considered to be the best capsule shape to store phase change material.

\subsubsection{Comparison with SHS System}

\section{Discharging Process in SHS System}

The results obtained from SHS system are compared with the combined system and are tabulated in Table 4. From Table 4, it is observed that at a constant charging temperature of $60^{\circ} \mathrm{C}$, the thermal energy retrieved is $1484.68 \mathrm{KJ}$ from the combined system where as the energy retrieved $1406.83 \mathrm{KJ}$ is only from SHS system, hence a combined system is more efficient and recommended.

\subsection{Selection of Parameters Using Fuzzy Logic}

The experimental results are analyzed using Fuzzy Logic to select the optimum parameters. Smaller the better 


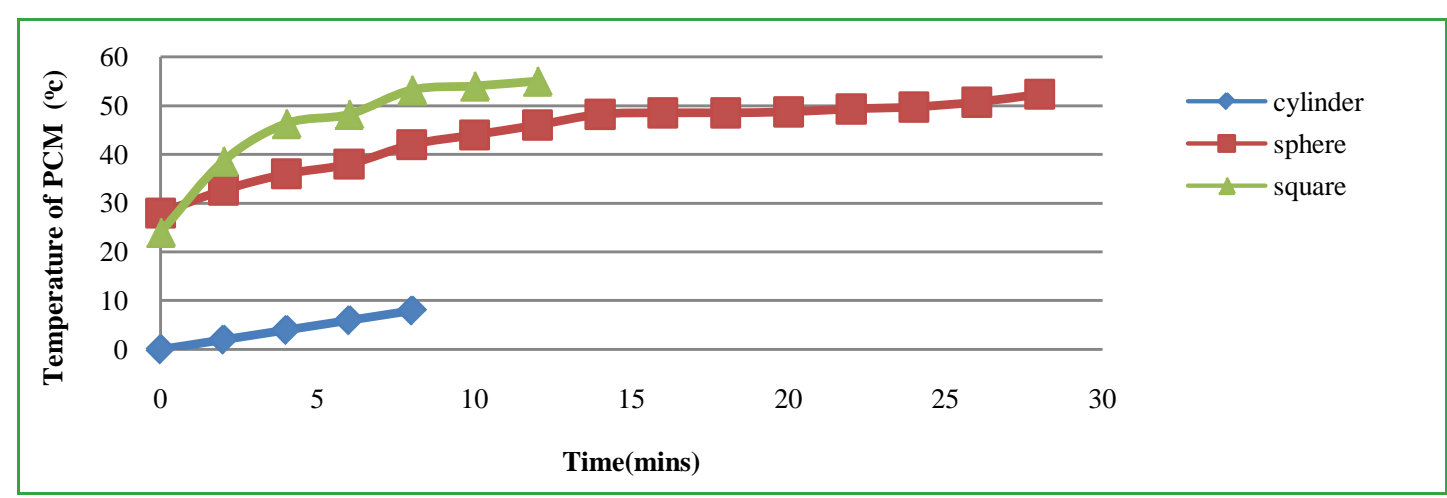

Figure 8. Effect of charging time on different capsule shapes.

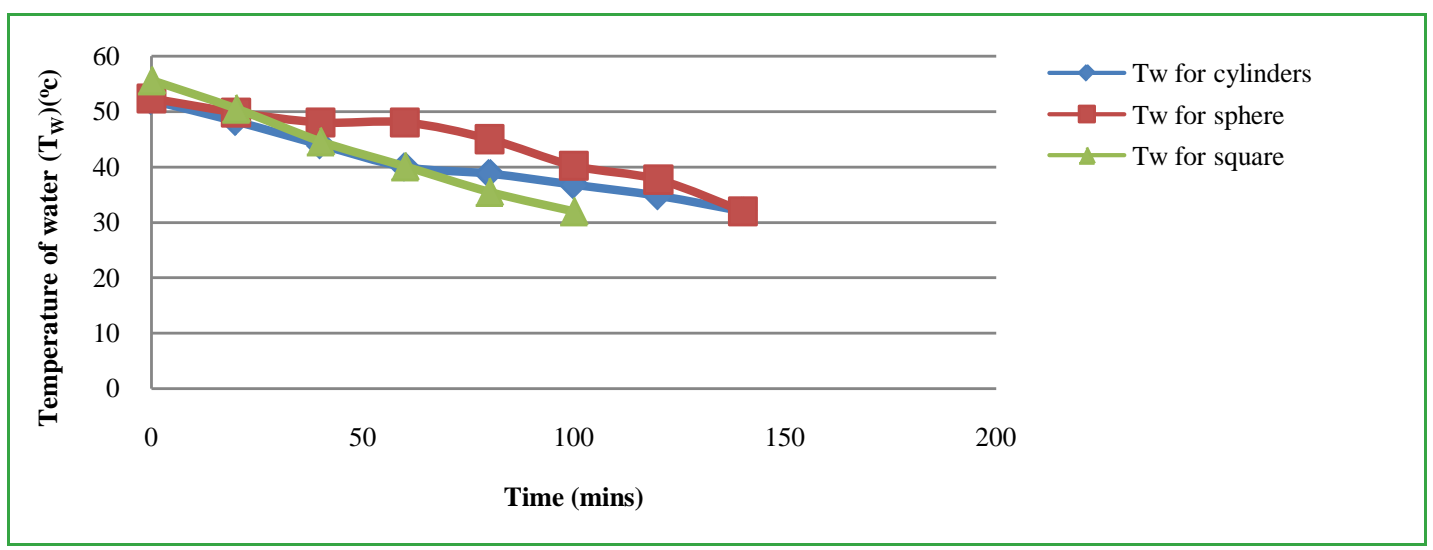

Figure 9. Effect of discharging time on different capsule shapes.

Table 4. Comparison of (SHS + LHS) and SHS.

\begin{tabular}{ccc}
\hline Status of description & TES (SHS + LHS) & SHS \\
\hline $\begin{array}{c}\text { Total volume of the TES tank (lit) } \\
\text { Total hot water withdrawn }\end{array}$ & 10 & 10 \\
\hline \multicolumn{1}{c}{ Energy stored (KJ) } & 57.12 \\
\hline Energy stored in the sodium thiosulfate pentahydrate & 1660.20 & 1172.08 \\
Total energy stored & 1484.68 & 1406.83 \\
Heat recovered from the system in the form of Hot water during discharge & 140 & 100 \\
Energy retrieval time (min)
\end{tabular}

formula is used to find $\mathrm{S} / \mathrm{N}$ ratios of the experimental values of charging time. To find $\mathrm{S} / \mathrm{N}$ ratios of the experimental results of discharging time, the larger the better formula is used and the values are tabulated in Table 5 .

The structure built for this study is a two input-one-output Fuzzy Logic unit as shown in Figure 10(a). The input variables of the Fuzzy Logic system in this study are the $\mathrm{S} / \mathrm{N}$ ratios of responses charging time and discharging time. They are converted into linguistic fuzzy subsets using membership functions of a triangle form, as shown in Figure 10(b), and are uniformly assigned into three fuzzy subsets-low (L), medium (M) and high $(\mathrm{H})$ grade. The output variable of this analysis is the comprehensive output measure (COM) and the comprehensive output measure (COM) is generated using MATALAB, which is shown in Table 6. Membership functions used for this work are of a triangle form, as shown in Figure 10(b). Unlike the input variables, the output variable is assigned into relatively nine subsets i.e., very very low (VVL), very low (VL), small (S), medium low 
K. D. Reddy et al.

Table 5. S/N ratios of experimental values.

\begin{tabular}{|c|c|c|c|c|c|c|c|}
\hline Experimental run & $\begin{array}{l}\text { Flow } \\
\text { rate }\end{array}$ & $\begin{array}{l}\text { HTF inlet temp } \\
\left(\mathrm{T}_{\mathrm{HTF}}\right)\end{array}$ & Capsule shape & $\begin{array}{l}\text { Charging } \\
\text { time }\end{array}$ & $\begin{array}{l}\text { Discharging } \\
\text { time }\end{array}$ & S/NRA1 & S/NRA2 \\
\hline 1 & 2 & 60 & 1 & 10 & 140 & -20 & 42.92256 \\
\hline 2 & 2 & 60 & 2 & 32 & 140 & -30.103 & 42.92256 \\
\hline 3 & 2 & 60 & 3 & 18 & 100 & -25.1055 & 40 \\
\hline 4 & 2 & 58 & 1 & 14 & 100 & -22.9226 & 40 \\
\hline 5 & 2 & 58 & 2 & 34 & 120 & -31.1261 & 40 \\
\hline 6 & 2 & 58 & 3 & 18 & 80 & -25.1055 & 38.0618 \\
\hline 7 & 2 & 56 & 1 & 16 & 100 & -24.0824 & 40 \\
\hline 8 & 2 & 56 & 2 & 36 & 100 & -31.1261 & 40 \\
\hline 9 & 2 & 56 & 3 & 18 & 80 & -25.1055 & 38.0618 \\
\hline 10 & 4 & 60 & 1 & 08 & 140 & -18.0618 & 42.92256 \\
\hline 11 & 4 & 60 & 2 & 28 & 140 & -28.9432 & 42.92256 \\
\hline 12 & 4 & 60 & 3 & 12 & 100 & -21.5836 & 40 \\
\hline 13 & 4 & 58 & 1 & 11 & 100 & -21.5836 & 40 \\
\hline 14 & 4 & 58 & 2 & 32 & 120 & -30.103 & 40 \\
\hline 15 & 4 & 58 & 3 & 18 & 80 & -25.1055 & 38.0618 \\
\hline 16 & 4 & 56 & 1 & 16 & 100 & -22.9226 & 40 \\
\hline 17 & 4 & 56 & 2 & 32 & 100 & -30.103 & 40 \\
\hline 18 & 4 & 56 & 3 & 18 & 80 & -25.1055 & 38.0618 \\
\hline
\end{tabular}

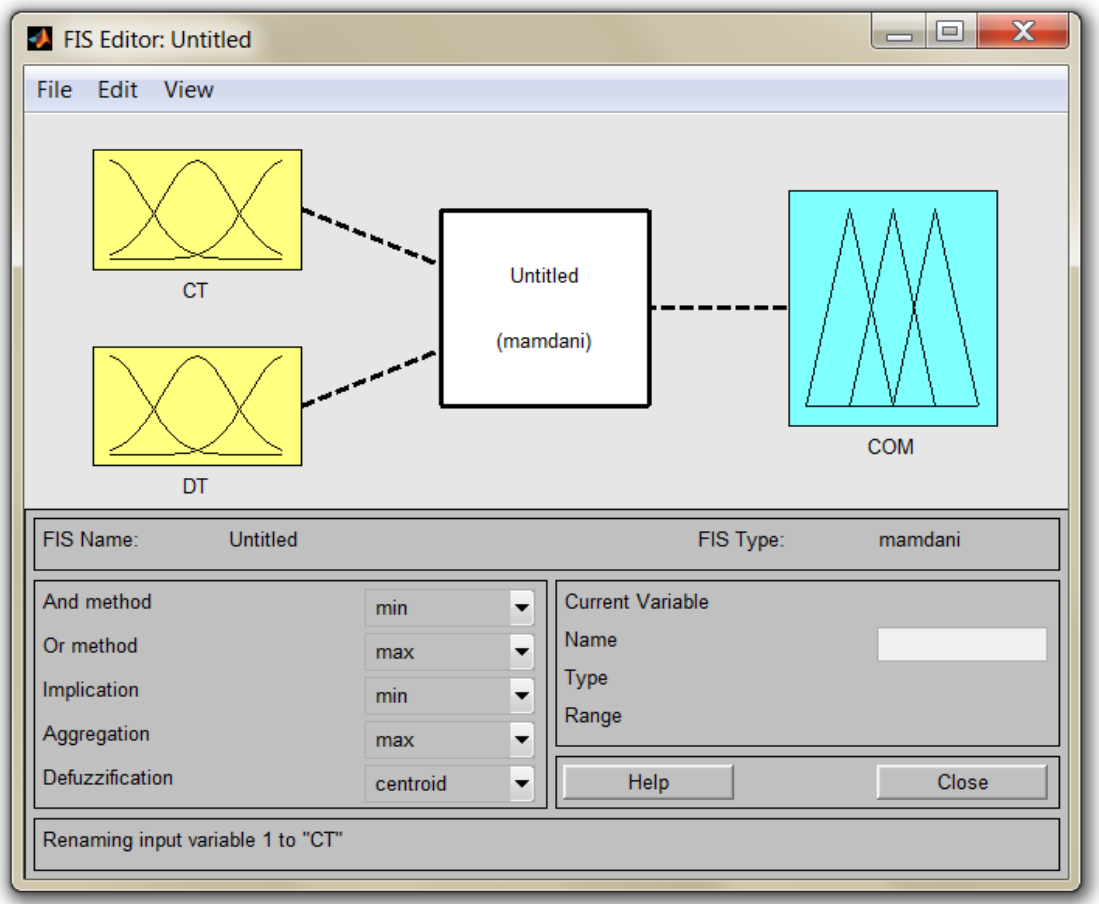

(a) 


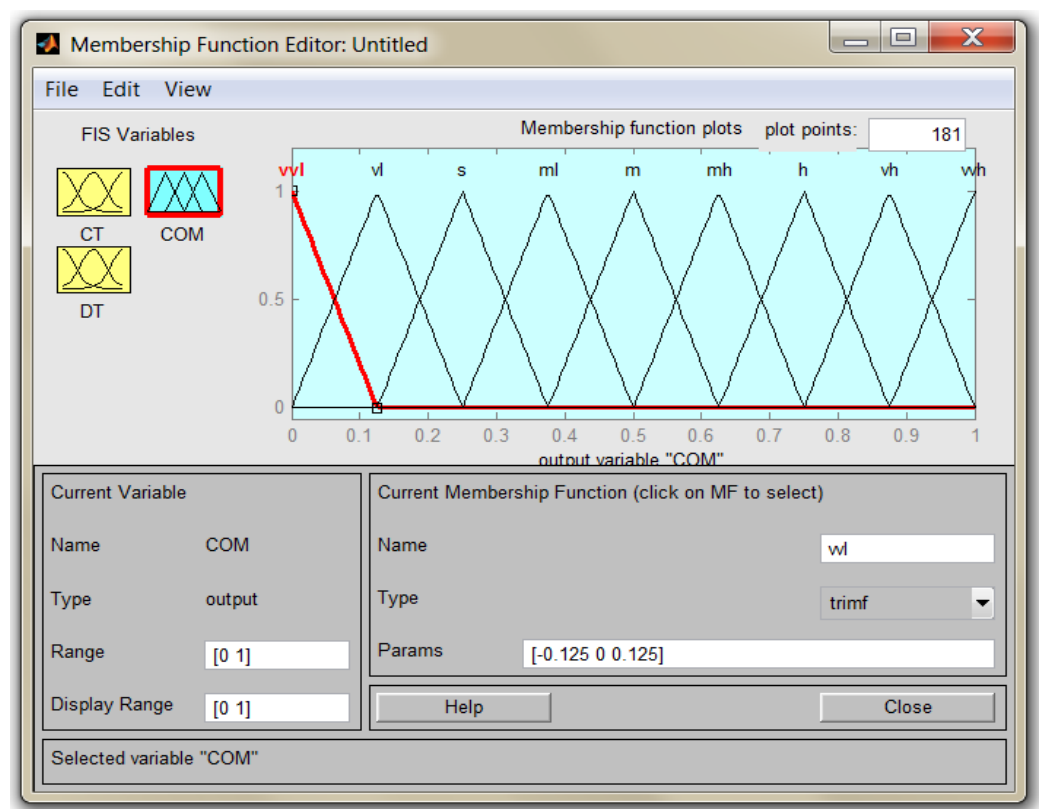

(b)

Figure 10. (a) Two input-one-output Fuzzy Logic unit and membership functions; (b) Membership functions for COM.

Table 6. COM for parameters selection.

\begin{tabular}{|c|c|c|c|c|}
\hline Sl. no. & Flow rate & HTF inlet temperature & Capsule shape & Comprehensive output measure (COM) \\
\hline 1 & 2 & 60 & 1 & 0.9615 \\
\hline 2 & 2 & 60 & 2 & 0.3462 \\
\hline 3 & 2 & 60 & 3 & 0.5283 \\
\hline 4 & 2 & 58 & 1 & 0.6455 \\
\hline 5 & 2 & 58 & 2 & 0.1221 \\
\hline 6 & 2 & 58 & 3 & 0.4266 \\
\hline 7 & 2 & 56 & 1 & 0.5993 \\
\hline 8 & 2 & 56 & 2 & 0.1221 \\
\hline 9 & 2 & 56 & 3 & 0.4266 \\
\hline 10 & 4 & 60 & 1 & 0.9572 \\
\hline 11 & 4 & 60 & 2 & 0.4100 \\
\hline 12 & 4 & 60 & 3 & 0.6933 \\
\hline 13 & 4 & 58 & 1 & 0.6933 \\
\hline 14 & 4 & 58 & 2 & 0.2304 \\
\hline 15 & 4 & 58 & 3 & 0.4266 \\
\hline 16 & 4 & 56 & 1 & 0.6455 \\
\hline 17 & 4 & 56 & 2 & 0.2304 \\
\hline 18 & 4 & 56 & 3 & 0.4266 \\
\hline
\end{tabular}

$(\mathrm{ML})$, medium $(\mathrm{M})$, medium high $(\mathrm{MH})$, high $(\mathrm{H})$, very high $(\mathrm{VH})$ and very very high $(\mathrm{VVH})$ grade. Then, 9 fuzzy rules are defined and shown in Table 7. 
After analyzing the comprehensive output measure (COM) using Taguchi a rank will be obtained. The rank which is shown in Table 8 indicates the effect of input parameters on the responses i.e., the rank-1 indicates that the capsule shape has more effect on charging time and discharging time respectively.

Figure 11 represents the average COM values of flow rate, HTF inlet temperature and capsule shape and it is observed that the optimum parameter combination for these values are as follows.

Flow rate at level 2: 4 lit/min.

HTF inlet temperature at level 3: $60^{\circ} \mathrm{C}$.

PCM capsule shape at level 1: cylindrical capsule shape.

Table 7. Rules for process parameter.

\begin{tabular}{ccccccc}
\hline Sl. no. & S/N ratio for & \multicolumn{3}{c}{$\begin{array}{c}\text { S/N ratio for } \\
\text { discharging time }\end{array}$} & Comprehensive output \\
measure (COM)
\end{tabular}

Table 8. Selection of parameters.

\begin{tabular}{cccc}
\hline Level & Flow rate & HTF inlet temperature & Capsule shape \\
1 & 0.4642 & 0.4084 & 0.7504 \\
2 & 0.5237 & 0.4241 & 0.2435 \\
3 & $--------~$ & 0.6494 & 0.5069 \\
Delta & 0.0595 & 0.2410 & 1 \\
Rank & 3 & 2 & 1 \\
\hline
\end{tabular}

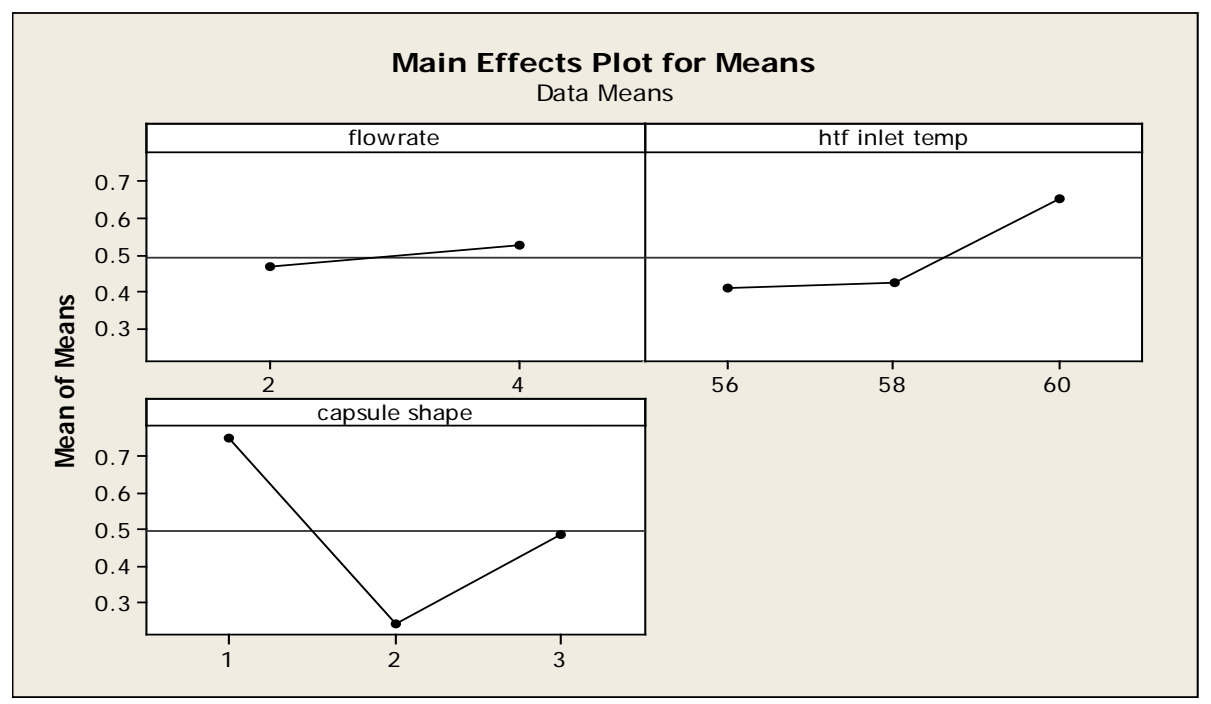

Figure 11. COM value for each factor at each level. 
Table 9. Confirmation test results.

\begin{tabular}{cccccc}
\hline & $\begin{array}{c}\text { Flow rate } \\
\text { (lit/min) }\end{array}$ & $\mathrm{T}_{\mathrm{HTF}}\left({ }^{\circ} \mathrm{C}\right)$ & Shape of the capsule & Charging time (min) & $\begin{array}{c}\text { Discharging time } \\
(\mathrm{min})\end{array}$ \\
\hline Fuzzy logics & 4 & 60 & 1 & 6 & 138 \\
Experimental values & 4 & 60 & 1 & 8 & 140 \\
\hline
\end{tabular}

\section{Conclusions}

From the results the following conclusions have been drawn:

- The effect of mass flow rate of heat transfer fluid at $4 \mathrm{lit} / \mathrm{min}$ and heat transfer fluid inlet temperature at $60^{\circ} \mathrm{C}$ is more on charging time when compared to other. Hence, it is concluded that higher flow rates and higher inlet temperaStures of heat transfer fluid are recommended.

- From the results, it is also observed that the total energy stored and energy retrieval time are high in combined Sensible heat storage (SHS) and Latent heat storage (LHS) system than conventional sensible heat storage system (SHS). Hence, combined SHS and LHS are recommended for thermal energy storage systems.

- The charging time, surface area to volume ratio and energy retrieval time is more for cylindrical PCM capsule shape compared to others. Hence, cylindrical PCM capsule is recommended for filling PCM.

- From Table 9, it is observed that the experimental results and fuzzy optimized results are quite close to each other. Hence, it is concluded that Fuzzy Logics technique can be efficiently applied to optimize the phase change materials parameters.

\section{Acknowledgements}

Authors would like to acknowledge the technical staff of Mechanical Engineering Department, S. V. University, Tirupati for their help in this experimentation.

\section{References}

[1] Regin, F., Solanki, S.C. and Saini, J.S. (2009) An Analysis of a Packed Bed Latent Heat Thermal Energy Storage System Using PCM Capsules: Numerical Investigation. Renewable Energy, 34, 1765-1773. www.elsevier.com/locate/renene http://dx.doi.org/10.1016/j.renene.2008.12.012

[2] Singh, A., Datta, S., Mahapatra, S.S., Singha, T. and Majumdar, G. (2011) Optimization of Bead Geometry of Submerged Arc Weld Using Fuzzy Based Desirability Function Approach. Journal of Intelligent Manufacturing, 24, 35-44. http://dx.doi.org/10.1007/s10845-011-0535-3

[3] Sharma, A. and Chen, C.R. (2009) Solar Water Heating System with Phase Change Materials. International Review of Chemical Engineering (I.RE.CH.E.), 1, 297-307.

[4] Sharma, A., Tyagi, V.V., Chen, C.R. and Buddhi, D. (2007) Review on Thermal Energy Storage with Phase Change Materials and Applications. Renewable and Sustainable Energy Reviews, 13, 318-345

[5] Kanimozhi, B, Ramesh Bapu, B.R. and Sivashanmugam, M. (2010) Enhancement of Solar Thermal Storage System Using PCM. National Journal on Advances in Building Sciences and Mechanics, 1, 48-52.

[6] Maheswari, U. and Reddy, R.M. (2013) Thermal Analysis of Thermal Energy Storage System with Phase Change Material. International Journal of Engineering Research and Applications (IJERA), 3, 617-622.

[7] Vikram, D., Kaushik, S., Prashanth, V. and Nallusamy, N. (2006) An Improvement in the Solar Water Heating Systems Using Phase Change Materials. Proceedings of the International Conference on Renewable Energy for Developing Countries, Denver, 8-13 July 2006, 409-416.

[8] Oroa, E., Gila, A., Miroa, L., Peiroa, G., Alvarezb, S. and Cabezaa, L.F. (2012) Thermal Energy Storage Implementation Using Phase Change Materials for Solar Cooling and Refrigeration Applications. Energy Procedia, 30, 947-956.

[9] Rajyalakshmi, G. and Venkata Ramaiah, P (2013) Optimization of Process Parameters of Wire Electrical Discharge Machining Using Fuzzy Logic Integrated with Taguchi Method. International Journal of Scientific Engineering and Technology, 2, 600-606.

[10] Lu, H.S., Chen, J.Y. and Chung, Ch.-T. (2008) The Optimal Cutting Parameter Design of Rough Cutting Process in Side Milling. Journal of Achievements in Materials and Manufacturing Engineering, 29, 183-186. 
[11] Tanishita, I. (1970) Present Situation of Commercial Solar Water Heater in Japan. Proceedings of the ISES Conference, Melbourne, 2-6 March 1970, Paper No. 2/73, 67-78.

[12] Archibald, J. (1999) Building Integrated Solar Thermal Roofing Systems History, Current Status, and Future Promise. Proceedings of the Solar Conference, American Solar Energy Society, American Institute of Architects, 95-100.

[13] Chandrasekaran, M. and Devarasiddappa, D. (2012) Development of Predictive Model for Surface Roughness in End Milling of Al-SiCp Metal Matrix Composites Using Fuzzy Logic. International Scholarly and Scientific Research \& Innovation, 6, 928-933.

[14] Fatih Demirbas, M. (2006) Thermal Energy Storage and Phase Change Materials: An Overview. Energy Sources, Part $B, 1,85-95$.

[15] Mehling, H. and Cabeza, L.F. (2008) Heat and Cold Storage with PCM. An up to Date Introduction into Basics and Applications. Springer, Berlin.

http://www.springer.com/chemistry/industrial+chemistry+and+chemical+engineering/book/978-3-540-68556-2

[16] Ercan Ataer, O. (2006) "Storage of Thermal Energy, in Energy Storage Systems” in Encyclopedia of Life Support Systems (EOLSS), Developed under the Auspices of the UNESCO. Eolss Publishers, Oxford. http://www.eolss.net

[17] Karthikeyan, R., Jaiganesh, S. and Pai, B.C. (2002) Optimization of Drilling Characteristics for Al/SiCp Composites Using Fuzzy/GA. Metals and Materials International, 8, 163-168. http://dx.doi.org/10.1007/BF03027013

[18] Khot, S.A., Sane, N.K. and Gawali, B.S. (2011) Experimental Investigation of Phase Change Phenomena of Paraffin Wax inside a Capsule. International Journal of Engineering Trends and Technology, 2, 67-71.

[19] Vijay Padmaraju, S.A., Viginesh, M. and Nallusamy, N. (2008) Comparative Study of Sensible and Latent Heat Storage Systems Integrated with Solar Water Heating Unit. International Conference on Renewable Energy and Power Quality, Santander.

[20] Hasenöhrl, T. (2009) An Introduction to Phase Change Materials as Heat Storage Mediums. Project Report, 160 Heat and Mass Transport, Lund.

[21] Bhatt, V.D., Gohil, K. and Mishra, A. (2010) Thermal Energy Storage Capacity of Some Phase Changing Materials and Ionic Liquids. International Journal of ChemTech Research CODEN (USA): IJCRGG, 2, 1771-1779. 
Scientific Research Publishing (SCIRP) is one of the largest Open Access journal publishers. It is currently publishing more than 200 open access, online, peer-reviewed journals covering a wide range of academic disciplines. SCIRP serves the worldwide academic communities and contributes to the progress and application of science with its publication.

Other selected journals from SCIRP are listed as below. Submit your manuscript to us via either submit@scirp.org or Online Submission Portal.
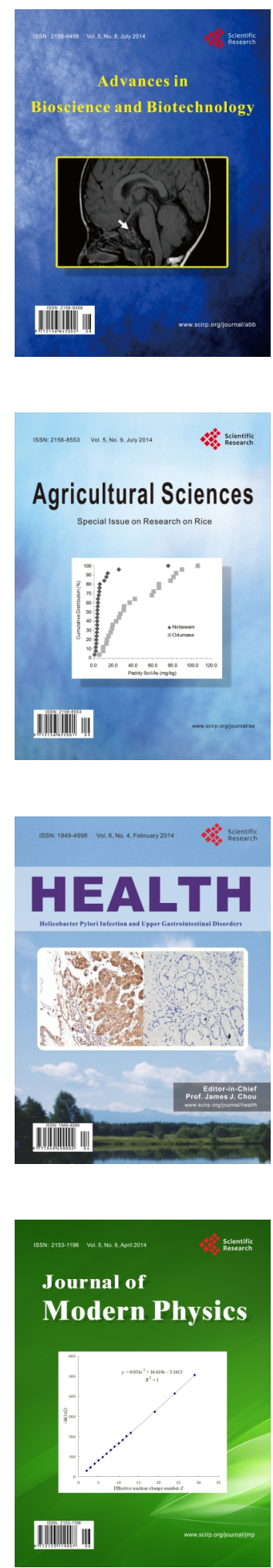
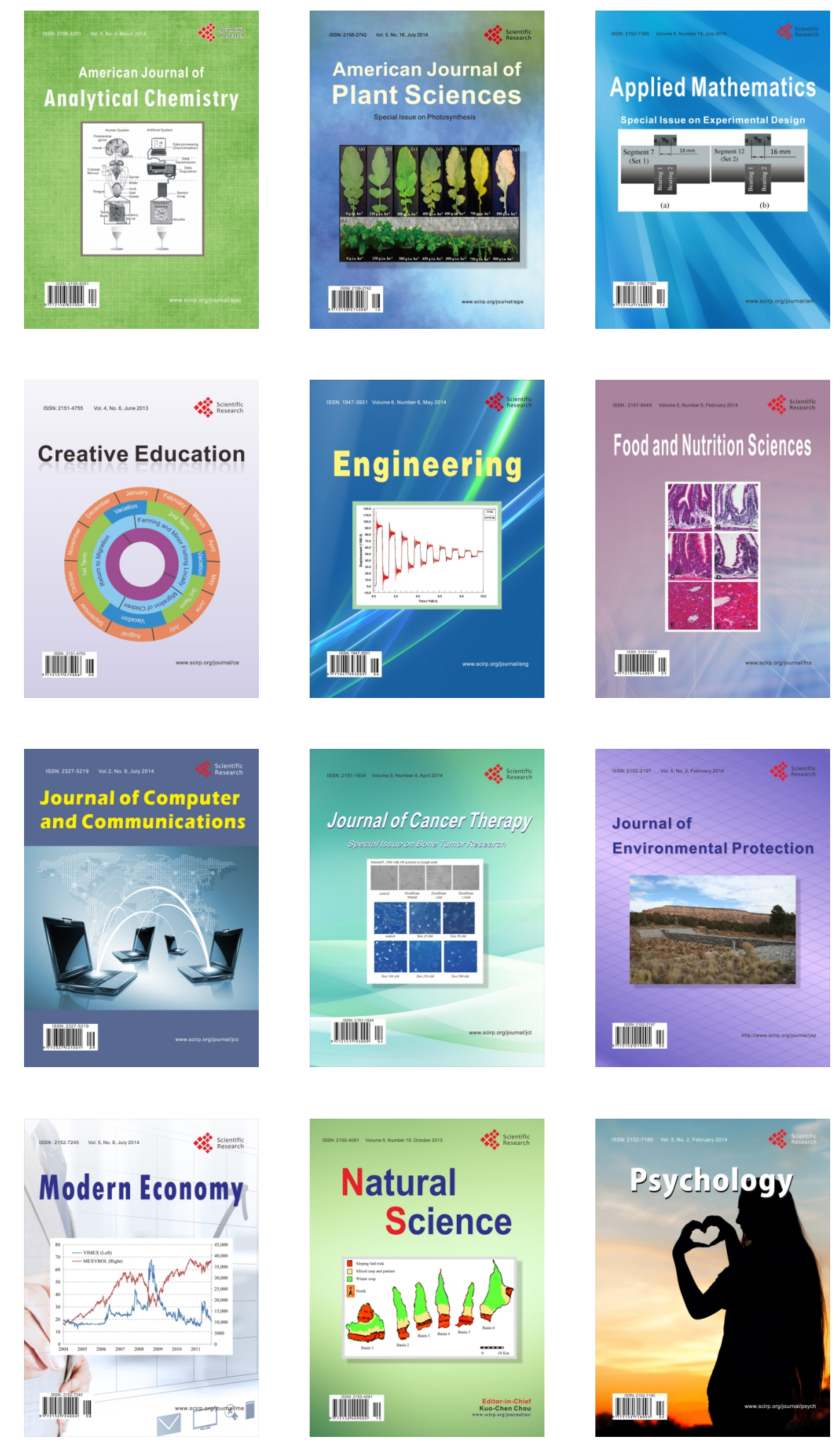